\title{
O POTENCIAL DA ENTREVISTA EM CONTEXTO EDUCATIVO: UMA EXPERIÊNCIA INVESTIGATIVA
}

Carmen Domingues Reste* Universidade de Aveiro (UA)

RESUMO: Subjaz a este artigo uma tese de doutoramento ${ }^{1}$, recentemente concluída, que usa as representações sociais como formas de conhecimento prático que permitem a compreensão do campo educativo. Esse estudo desenvolveu-se de acordo com uma metodologia qualitativa e o instrumento principal de recolha de dados foi a entrevista individual, semiestruturada, não interventiva. Os sujeitos principais foram alunos de uma escola do Ensino Secundário com $3^{\circ}$ Ciclo. Os resultados que aqui apresentamos mostram-nos como a mera participação no processo de recolha de dados levou os participantes a uma metarreflexão potenciadora tanto de uma transição epistemológica como de uma transição ecológica, assumindo-se como agentes conscientes e ativos de mudança na escola.

Palavras-chave: Entrevista. Investigação qualitativa. Representações sociais. Escola reflexiva. Educação intercultural.

\section{INTERVIEW'SPOTENTIAL IN THE EDUCATIONAL CONTEXT - AN INVESTIGATIVE EXPERIENCE}

ABSTRACT: This paper is based on a recently completed doctoral thesis that uses social representations as forms of practical knowledge, a knowledge that allows the comprehension of the educational field. The study was developed according to a qualitative methodology and the main data collection instrument was the individual, semi-structured, non-interventive interview. The main subjects were students in a school of lower and higher secondary education ("Ensino Secundário com 30 Ciclo"). The results presented here show us how the mere participation in the data collection process led participants to a self-reflection that can promote both an epistemological transition and an ecological transition, assuming themselves as conscious and active agents of change in school.

Keywords: Interview. Qualitative Research. Social Representations. Reflective School. Intercultural Education.

http://dx.doi.org/10.1590/0102-4698138927

" Doutora em Didática e Formação pela Universidade de Aveiro. Membro Efetivo do LEIP (Laboratório de Investigação em Educação em Português) da Universidade de Aveiro. Professor do QE, em exercício de funções docentes na Escola Secundária Oliveira Júnior, São João da Madeira, Portugal. E-mail: carmen.reste@LIVE.ua.pt 


\section{INTRODUCุÃO}

O projeto de investigação que deu origem a este artigo partiu da diversidade cultural presente nas escolas portuguesas e procurou, entre outros objetivos, compreender como é que as representações sociais e a construção da identidade/alteridade influenciam os (des)encontros entre alunos estrangeiros e autóctones e, também, detetar necessidades ao nível de uma educação intercultural em que o reconhecimento da identidade e da alteridade - enquanto (re) construção - potencie relações humanamente significativas. Assim, os objetivos deste artigo são a) expor algumas das implicações da participação dos entrevistados sobre o próprio processo da recolha de dados e b) refletir sobre a importância deste processo que, por si só, pode potenciar a intervenção. ${ }^{1}$

A entrevista é recomendada como uma das metodologias para a recolha de dados para analisar as Representações Sociais (RS), entendendo que os participantes contribuem, ativamente, para a sua análise. Apesar de os sujeitos principais do nosso estudo serem os alunos - estrangeiros e autóctones - que frequentam uma escola do Ensino Secundário com $3^{\circ} \mathrm{Ciclo}^{2}$, também entrevistamos, complementarmente, alguns dos Encarregados de Educação (E.E.) desses alunos (A) e seus professores que assumiam a função de Diretores de Turma (D.T.). Por fim, entrevistamos o Diretor da escola (D).

Os resultados que aqui apresentamos referem-se às últimas questões do guia da entrevista, que procuravam a sua validação junto dos participantes e cuja análise integrava a última dimensão da matriz categorial do estudo- "Participação dos sujeitos no estudo".

\section{ENQUADRAMENTO TEÓRICO}

\section{Investigar RS em contexto educativo: perspetivas teórico- metodológicas}

Michel Gilly (1989), um dos primeiros autores a debruçar-se sobre o estudo das RS para compreender o campo educativo, considera que o mesmo é um campo privilegiado para esclarecer o papel daquelas nas relações dos grupos sociais com o objeto das suas representações. Essas representações são feitas de contradições perceptíveis, sendo possível, num dado momento, analisá-las e organizá-las em torno de significações que justificam as práticas (GILLY, 1989).

Noque se refere às justificações dos resultados escolares em função das desigualdades sociais, aquele autor constata que os diferentes agentes 
educativos as remetem, frequentemente, para fora do aparelho escolar e, desta forma, a construção representativa fortalece a representação do senso comum, sem questionar as estruturas fundamentais da escola e o seu sistema de funcionamento (GILLY, 1989).

Se é certo que as RS não podem ser tomadas como uma "panaceia universal", elas permitem-nos, todavia, ampliarmos a compreensão dos fatos estudados, recolocando-os em campos mais vastos de significação social, dos quais elas estão dependentes (GILLY, 1989). Sem esquecer a influência recíproca entre as RS e os seus efeitos, sublinhamos que o seu estudo é determinante para a compreensão da sua influência e do seu impacto nas interações que se estabelecem na escola, bem como no autoconceito e na autoestima dos alunos (AMADO; CUSOÉ; VAZ-REBELO, 2013).

Metodologicamente, a teoria das RS não é prescritiva em relação a nenhum método em particular (Moscovici, 1984). Todavia, a metodologia qualitativa favorece, por um lado, a descoberta de fenômenos emergentes relativos às mudanças sociais e ao pluralismo, nomeadamente o cultural, e, por outro, a apreensão do caráter evolutivo e dinâmico dos fenômenos relativamente aos seus contextos e momentos históricos (JODELET, 2003).

Embora os estudos das RS não possam ser replicáveis, dado que as mesmas variam de cultura para cultura e mudam com o tempo dentro de uma própria cultura, a metodologia qualitativa é aconselhada quando, numa sociedade culturalmente diversa e em mudança, pretendemos investigar a pluralidade dos grupos e as suas pertenças sociais, a novidade das situações e a singularidade dos seus devires (JODELET, 2003).

Abric (2001) distingue, por um lado, os "métodos interrogativos", que consistem na recolha das expressões dos indivíduos no que concerne ao objeto da representação, podendo ser usado para esse efeito a entrevista, o questionário, os desenhos e os gráficos de apoio e/ ou a abordagem monográfica; e, por outro lado, os "métodos associativos", que procuram obter uma expressão verbal mais espontânea e menos controlada, podendo ser usada a evocação ou associação livre.

No estudo que aqui apresentamos, optamos pelos "métodos interrogativos", nomeadamente pela entrevista como técnica de recolha de dados, cuja importância e pertinência passamos a explicar.

\section{O paradigma qualitativo de investigação e a entrevista como técnica de recolha de dados}

Tomando como referência o conceito de paradigma proposto por Lincoln e Guba (2006) como um conjunto básico de crenças que 
originam a ação e a categorização dos paradigmas de investigação revistos por Amado, Cusoé e Vaz-Rebelo (2013), sublinhamos desde logo que a investigação qualitativa exclui uma racionalidade de tipo linear na relação processo-produto, de lógica simplista e redutora da complexidade dos fenômenos que são explicados extrínseca e externamente. $\mathrm{O}$ paradigma qualitativo de investigação procura, antes, a compreensibilidade mais globalizante dos fenômenos, assente na sua organização intrínseca e na sua ecologia, no uso de uma "racionalidade complexa" (MORIN, 1994) e de uma "racionalidade crítica" defendida por autores como Apple (1999) e McLaren e Gutierrez (2000), que advogam que a investigação também deve promover a transformação social, a autonomia dos sujeitos, o repensar dos objetivos da Educação, a sua natureza, a sua metodologia, bem como a emancipação dos agentes educativos, oferecendo-lhes instrumentos críticos de análise da sua própria ação.

Para além de uma racionalidade complexa e crítica, e em função de uma perspectiva construtivista do conhecimento, a metodologia de abordagem qualitativa, embora exclua a generalização dos resultados e a sua homogeneização, possibilita encontrar significados que permitem a compreensão de uma realidade desde logo situada e particular. Trata-se de uma pesquisa cujo objetivo é obter junto dos participantes a informação que permita a compreensão de certos comportamentos, modos de estar e de pensar, procurando, desse modo, colaborar para a resolução dos problemas existentes no contexto e a melhoria do mesmo (AMADO, 2013). Trata-se ainda de um tipo de investigação cujos processos de interpretação de dados privilegiam a voz dos intervenientes no estudo (BOGDAN; TAYLOR, 1975; DENZIN; LINCOLN, 2006).

O paradigma qualitativo de investigação situa-se, pois, num dos "critérios emergentes" para a construção do saber: a "reconciliação entre a ética e a epistemologia", uma vez que esse critério respeita padrões como comunidades de discurso específicas e locais, a subjetividade crítica, a reciprocidade nas relações de pesquisa em vez da relação hierárquica, entre outros (BOGDAN; TAYLOR, 1975).

Dentro desse paradigma, a entrevista é recomendada por Denise Jodelet para o estudo das RS, por permitir relacionar as mesmas com o contexto e os atores dos fenômenos estudados (JODELET, 2003). No âmbito do estudo das RS, essa técnica de recolha de dados é valorizada e adquire todo o seu sentido, dado que se pretende captar nos discursos as opiniões, as crenças, os sentimentos, as experiências passadas e intenções futuras através do acesso direto à informação (CANNELL; KAHN, 1992; RUQUOY, 2005). A sua 
importância e pertinência, nesta matéria, prende-se ainda com o fato de a expressão discursiva que nela ocorre favorecer, conscientemente ou não, a utilização de mecanismos psicológicos, cognitivos e sociais, entendendo que os participantes cooperam ativamente no processo de análise das mesmas (ABRIC, 2000).

Uma entrevista é literalmente uma "entre - vista", uma troca de pontos de vista entre duas pessoas, neste caso, o entrevistador e o entrevistado, que conversam sobre um tema de mútuo interesse. Ela é uma "conversação estruturada", cuja força reside, precisamente, na apreensão da multiplicidade de pontos de vista dos sujeitos sobre um tema, de modo a construir uma imagem da diversidade e controvérsia do mundo humano (KVALE, 1996).

Sendo a entrevista qualitativa um dos processos fundamentais de comunicação e de interação humana, permite ao pesquisador retirar dela não apenas as informações, mas também as reflexões que os sujeitos fazem sobre as mesmas; pretende descrever não apenas os temas que aborda, mas sobretudo o significado desses temas na vida e no mundo dos entrevistados (AMADO; FERREIRA, 2013; FLICK, 2005). Além disso, a entrevista permite produzir material verbal que é, ao mesmo tempo, material simbólico. Colocar questões é estimular a conduta verbal que proporcionará indicadores de certas características do indivíduo, do seu grupo de pertença, dos outros grupos e das relações que lhes estão subjacentes, possibilitando a conversão da conduta simbólica em dados científicos (CARTWRIGHT, 1992).

A entrevista semidiretiva ou semiestruturada não é nem uma conversação aberta, nem um questionário altamente estruturado, e tem três propósitos: a) permitir o acesso ao não observável, provocando "uma espécie de introspeção" e o acesso às representações atuais mesmo de acontecimentos passados; b) identificar e relacionar esses "não-observáveis" com variáveis e relações; c) ajuizar sobre a coerência ou incoerência dos resultados e validar os dados obtidos, ao realizar, por exemplo, a triangulação de fontes (AMADO; FERREIRA, 2013).

\section{Investigar em didática: a escola reflexiva}

Numa crítica aos modelos de pesquisa que considera predominantes, Bronfenbrenner (2002) defende que os mesmos devem ter em conta o "ambiente ecológico" no qual os indivíduos se desenvolvem tal como esse ambiente é "percebido", e não conforme uma existência "objetiva" do mesmo. Na sua opinião, os modelos de pesquisa devem usar lentes científicas que valorizem as capacidades e as forças humanas, quer do pesquisador, quer dos participantes, para 
responder construtivamente às oportunidades ambientais. Para esse efeito, é necessário que o ser humano, sempre em desenvolvimento, veja também - para além das propriedades mutantes do seu ambiente imediato e do complexo de inter-relações dentro do microssistema - a interconexão entre os ambientes que constituem a sequência de estruturas ecológicas, como se de um conjunto de bonecas russas se tratasse, designadamente entre o micro, o meso, o exo e o macrossistema.

Nesta conformidade, para Bronfenbrenner (2002), ganha particular significado aquilo que o autor considera "o potencial inexplorado da pesquisa" que são as "transições ecológicas". Essas ocorrem sempre que a posição de uma pessoa no meio ambiente se altera, por exemplo, através da mudança de papel, ou seja, pela mudança de expectativas de comportamento associadas a determinada posição. Nas palavras do autor: "Os papéis têm um poder mágico de alterar a maneira pela qual a pessoa é tratada, como ela age, o que ela faz, e inclusive o que ela pensa e sente" (BRONFENBRENNER, 2002, p. 7).

Também Paulo Freire (1986) alerta para a importância da investigação, particularmente, no campo educativo. Segundo esse autor, o próprio ato de pesquisar é um "ato de conhecimento", "um ato educativo", capaz de possibilitar aos sujeitos pesquisados a reflexão e a superação do conhecimento anterior nos seus aspectos mais ingênuos. Como ato educativo, também a pesquisa não se deve limitar a uma simples recolha de dados, antes, deve procurar compreender de que forma os sujeitos entrevistados sentem o seu contexto de vida, ao mesmo tempo que lhes proporciona a possibilidade de esses perceberem como podem superar a mera constatação desse contexto.

Desse modo, o tema da entrevista e as suas questões podem ser entendidos como "tema gerador" e "palavras geradoras", uma vez que através da combinação de vários elementos outros se vão formando, e as significações constituídas até então se vão reconfigurando ou levam os sujeitos a reconfigurarem-se, ganhando agora uma consciência (mais) crítica (FREIRE, 1994). A reflexão que subjaz a essa consciência leva o sujeito a distanciar-se do mundo vivido, problematizando-o, descodificando-o criticamente, o que faz com que, nesse mesmo movimento de consciência, o homem se redescubra "como personagem que se ignorava e é chamada a assumir seu papel. [...] A consciência do mundo e a consciência de si crescem juntas e em razão direta" (FIORI, 1994, p. 8). Para esse efeito, os sujeitos pesquisados jamais podem ser reduzidos à mera condição de objeto de pesquisa, ou informantes, sendo a investigação concebida numa relação de horizontalidade, capaz de superar a subalternidade dos mesmos (FREIRE, 1986). 
A investigação em Didática, particularmente, visa também o questionamento e a intervenção, procurando uma relação frutífera entre a realidade e a teorização sobre a mesma. Dessa forma, e situando-se dentro do paradigma construtivista, a investigação em Didática advoga à escola uma postura genericamente reflexiva por parte de todos os intervenientes - alunos, professores, especialistas em educação, etc., com vista a obter "um saber mais integrado, mais bolístico, mais diretamente ligado à prática, mais situado e mais rápido nas respostas a obter" (ALARCÃO, 2001, p. 27)3.

Atendendo a um paradigma emergente tanto de investigação como de formação para este terceiro milénio, urge a (re)construção de conhecimento na "multi e transdisciplinaridade", onde seja reestabelecido o diálogo e a confiabilidade entre as diferentes classes sociais, culturas e religiões (TAVARES; ALARCÃO, 2007, p. 102, 105-106). A concretização desse paradigma é tanto mais urgente quanto se verifica que relativamente à formação dos professores "a preparação profissional vocaciona-os para saberem trabalhar bem com alunos em grupos homogêneos" (CORTESÃO, 2012, p. 141). Assim, particularmente no que concerne ao contexto multicultural das escolas, o tema da diversidade e das diferenças tem vindo a ganhar proeminência como possibilidade de enriquecimento e reflexão didáticas que desperta articulações entre o social e o cultural (CANDAU, 2012).

Partindo da perspectiva da interculturalidade crítica, tem vindo a ser proposta uma "didática intercultural" que, no respeitante aos agentes educativos, os sujeite a um processo de capacitação e autonomia, que os leve a reconhecer as diferenças num horizonte de ação e emancipação, fazendo com que se interroguem também sobre o "nós" e "os Outros". No que concerne às práticas socioeducativas, tal didática deve ainda considerar as distintas expressões culturais dos alunos, o que supõe "multiplicar espaços e tempos de ensinar e aprender” (CANDAU, 2012, p. 11).

Também para Casa Nova (2011), a investigação que tenha em atenção esta epistemologia alternativa e emancipatória deve assumirse como uma "investigação comprometida", primeiramente, com a produção do conhecimento científico, com os sujeitos da investigação, e, por fim, com o próprio investigador e a sua forma de ser e de estar, ao mesmo tempo que recusa o compromisso com grupos sociais detentores de poder ou determinados contextos hegemônicos, assumindo-se neste último aspecto como "investigação descomprometida". 


\section{MÉTODO}

\section{A escola}

A escola onde desenvolvemos o nosso estudo situa-se no litoral norte de Portugal. Trata-se de uma escola secundária $\left(10^{\circ}, 11^{\circ}\right.$ e $12^{\circ}$ anos) que também integra o $3^{\circ}$ Ciclo do Ensino Básico ( $7^{\circ}$, $8^{\circ}$ e $9^{\circ}$ anos). Nela existe uma minoria de alunos estrangeiros, cerca de $10 \%$ do total de alunos, oriundos de 27 países, sendo as naturalidades mais representativas a do Brasil, dos PALOP ${ }^{4}$ e do Leste Europeu, designadamente a da Ucrânia.

\section{Caracterização dos participantes do estudo}

\section{Alunos}

No nosso estudo, os dois grupos de alunos foram selecionados segundo o critério da nacionalidade/cultura, tendo sido também considerado o critério da diversidade relativamente ao gênero, ao aproveitamento escolar e ao estatuto socioeconômico.

Por um lado, temos um grupo de alunos nascidos em Portugal, cujos pais são portugueses e que se consideram portugueses. Por outro lado, temos um grupo de alunos nascidos no estrangeiro, cujos pais também nasceram no estrangeiro e que se consideram, também, de uma outra nacionalidade/cultura que não a portuguesa. Os alunos entrevistados não têm entre si qualquer laço de parentesco.

QUADRO 1 - Caracterização dos alunos estrangeiros e dos alunos autóctones

\begin{tabular}{|c|c|c|c|c|c|}
\hline $\begin{array}{c}\text { Nome fictício } \\
\text { respeitando o } \\
\text { gênero }\end{array}$ & Idade & $\begin{array}{c}\text { País de origem do } \\
\text { aluno } \\
\text { (ou progenitores) }\end{array}$ & $\begin{array}{c}\text { Nome fictício } \\
\text { respeitando 0 } \\
\text { gênero }\end{array}$ & Idade & $\begin{array}{c}\text { País de } \\
\text { origem } \\
\text { do aluno }\end{array}$ \\
\hline "Vladislav" & 12 & Ucrânia & "Ramiro" & 12 & Portugal \\
\hline "Paul" & 12 & França & "Justino" & 12 & Portugal \\
\hline "Apollinarya" & 14 & Romênia & "Assunção" & 14 & Portugal \\
\hline "Júlio" & 14 & Brasil & "Gabriel" & 14 & Portugal \\
\hline "Odete" & 14 & Guiné-Bissau & "Benilde" & 14 & Portugal \\
\hline "Eugénia" & 20 & Angola & "Carolina" & 17 & Portugal \\
\hline "Olena" & 18 & Ucrânia & "Berta" & 19 & Portugal \\
\hline "Kirill" & 17 & Ucrânia & "Jaime" & 18 & Portugal \\
\hline "Lucas" & 17 & Venezuela & "Ronaldo" & 17 & Portugal \\
\hline "Ling" & 19 & China & "Joaquim" & 18 & Portugal \\
\hline
\end{tabular}

Fonte: Dados da pesquisa. 
Encarregados de Educação

Os E.E. ${ }^{5}$ dos alunos selecionados que manifestaram disponibilidade e interesse em ser entrevistados são os que constam nos quadros abaixo, onde se apresenta a sua caracterização socioprofissional.

QUADRO 2 - Caracterização dos Encarregados de Educação dos alunos estrangeiros e dos alunos autóctones

\begin{tabular}{|c|c|c|c|c|c|c|c|c|c|}
\hline $\begin{array}{c}\text { E.E. dos } \\
\text { alunos } \\
\text { estrangeiros }\end{array}$ & Idade $^{6}$ & Gênero & $\begin{array}{l}\text { País de } \\
\text { origem }\end{array}$ & Profissão & $\begin{array}{c}\text { E.E. dos } \\
\text { alunos } \\
\text { autóctones }\end{array}$ & Idade & Gênero & Nacionalidade & Profissão \\
\hline $\begin{array}{c}\text { E.E. } \\
\text { "Vladislav" }\end{array}$ & $39-44$ & $\mathrm{~F}$ & Ucrânia & $\begin{array}{l}\text { Desempre- } \\
\text { gada }\end{array}$ & $\begin{array}{c}\text { E.E. } \\
\text { "Ramiro" }\end{array}$ & $39-44$ & $\mathrm{~F}$ & Portuguesa & Professora \\
\hline E.E. "Paul” & $45-51$ & $\mathrm{~F}$ & França & Empresária & $\begin{array}{c}\text { E.E. } \\
\text { “Assunção" }\end{array}$ & $39-44$ & $\mathrm{~F}$ & Portuguesa & Professora \\
\hline $\begin{array}{c}\text { E.E. } \\
\text { "Apollinarya" }\end{array}$ & $45-51$ & M & Romênia & Professor & $\begin{array}{c}\text { E.E. } \\
\text { "Gabriel" }\end{array}$ & $45-51$ & $\mathrm{~F}$ & Portuguesa & Estudante \\
\hline E.E. "Júlio" & $39-44$ & $\mathrm{~F}$ & Brasil & $\begin{array}{c}\text { Funcionária } \\
\text { numa } \\
\text { empresa }\end{array}$ & $\begin{array}{c}\text { E.E. } \\
\text { "Benilde" }\end{array}$ & $39-44$ & $\mathrm{~F}$ & Portuguesa & Secretária \\
\hline
\end{tabular}

Fonte: Dados da pesquisa.

\section{Professores/ Diretores de Turma e Diretor da Escola}

Ao entrevistarmos os professores/ Diretores de Turma e o Diretor da escola, consideramos a sua importância enquanto agentes promotores de liderança a vários níveis e de um determinado tipo de cultura escolar, a sua imprescindibilidade enquanto "intelectuais transformadores" e "agentes reflexivos" capazes de efetivar uma interação entre as chamadas "teorias e práticas", fundamental para a melhoria da praxis escolar e sua evolução (CORTESÃO; STOER, 1995, p. 65). Na qualidade de Diretores de Turma, os professores entrevistados são agentes privilegiados, uma vez que, entre outras funções, cabe-lhes a articulação da comunicação entre os restantes professores da turma, os alunos, e os pais e Encarregados de Educação; a coordenação e a adequação das atividades, conteúdos, estratégias e métodos de trabalho à situação da turma e de cada aluno em particular; a articulação de atividades da turma com os pais e Encarregados de Educação, promovendo também a participação destes? 
O quadro abaixo condensa a caracterização socioprofissional dos professores e do Diretor da escola.

QUADRO 3 - Caracterização dos professores e do Diretor de escola

\begin{tabular}{|c|c|c|c|c|}
\hline D.T. & Idade & Gênero & Habilitações Acadêmicas & $\begin{array}{c}\text { Tempo de Serviço } \\
\text { Docente }^{8}\end{array}$ \\
\hline D.T. 1 & $45-51$ & F & Mestrado & $22-24$ \\
\hline D.T. 2 & $45-51$ & F & Licenciatura & $27-30$ \\
\hline D.T. 3 & $39-44$ & F & Mestrado & $22-24$ \\
\hline D.T. 4 & $45-51$ & F & Bacharelado & $27-30$ \\
\hline D.T. 5 & $28-34$ & F & Licenciatura & $5-10$ \\
\hline Diretor & $45-51$ & M & Pós-graduação & $27-30$ \\
\hline
\end{tabular}

Fonte: Dados da pesquisa.

\section{PROCEDIMENTOS METODOLÓGICOS E ÉTICOS}

\section{Preparação do guia da entrevista}

O nosso guião de entrevista é constituído, na sua grande maioria, por questões abertas, dado um dos princípios fundamentais da pesquisa qualitativa ser a espontaneidade em que os fenômenos emergem e evoluem, e ainda a importância da voz dos sujeitos da investigação que, quando expressa numa entrevista, não deve ser constrangida por um conjunto de questões fechadas (JODELET, 2003; LINCOLN; GUBA, 2006). Também tivemos em atenção que, no que se refere ao processo de categorização, os dados das questões abertas possibilitam uma categorização a posteriori, podendo o estudo ser mais fiel à realidade estudada, auxiliando ainda a interpretação das respostas.

O guia da entrevista teve por base o guia elaborado para o Estudo Exploratório, que foi testado e validado antecipadamente por colegas de doutoramento e alguns alunos (que não os sujeitos do estudo exploratório), sofrendo algumas alterações, tendo em conta os participantes e a realização das entrevistas do estudo em questão. Posteriormente, foi aperfeiçoado de forma a garantir a clareza e a adequação do questionário à população-alvo, tendo atenção às 
orientações de autores como Amado (2013), Cannell e Kahn (1992), Jodelet (2003), Kvale (1996) e Pardal e Correia (2011).

Após esta fase, o guia foi submetido à avaliação da DireçãoGeral de Inovação e Desenvolvimento Curricular (DGIDC), entidade incorporada no Ministério da Educação de Portugal. Depois da aprovação pela DGIDC, demos início aos procedimentos necessários para o estudo empírico.

\section{Trabalho de campo}

Após a anuência da Direção e do Conselho Pedagógico da escola, selecionada aleatoriamente, falamos com as Coordenadoras dos Diretores de Turma do Ensino Básico e Ensino Secundário, que, em reunião, identificaram as turmas multiculturais e os Diretores de Turma interessados em participar no estudo. Reunimo-nos com estes últimos e apresentamos o projeto, os objetivos e os critérios usados para a seleção das turmas e dos alunos.

Depois dos contactos dos Diretores de Turma junto dos alunos e, seguidamente, dos Encarregados de Educação, procedeuse à formalização desse assentimento para participação no projeto (AMADO, 2013). Posteriormente, de acordo com as recomendações e os passos metodológicos que devem anteceder a situação de pesquisa sugeridos por autores como Foddy (1996), Pardal e Correia (2011) e Kvale (1996), foram realizadas reuniões com os alunos de cada turma, onde a investigadora se apresentou, expôs as suas motivações, descreveu globalmente o Projeto de Investigação e explicou o objetivo geral do mesmo.

Explicamos que as entrevistas seriam gravadas em áudio, caso concordassem, expondo os motivos desse pedido, e asseguramos o caráter de anonimato inerente aos participantes e à escola em questão (AMADO, 2013). Informou-se, ainda, os alunos sobre o tempo previsto para a duração das entrevistas, sendo salvaguardado que, caso o desejassem, poderíamos marcar um ou mais momentos para a sua realização/conclusão, ou mesmo desistir a qualquer momento, caso assim o entendessem ou tivessem necessidade.

Segundo a calendarização acordada, as entrevistas individuais processaram-se entre janeiro e agosto de 2011. Salvo algumas exceções por indisponibilidade de agenda, entrevistamos, sequencialmente, os alunos de cada turma, os Encarregados de Educação e, finalmente, o respectivo Diretor de Turma. Findo este procedimento numa turma, passávamos à turma seguinte. O Diretor da escola foi o último a ser entrevistado. 
Embora fazer uma entrevista como técnica de recolha de dados não seja estabelecer uma conversação entre parceiros iguais, uma vez que o investigador define e controla a situação e segue, criticamente, as respostas que lhe são dadas (KVALE, 1996), procuramos estabelecer uma interação que respeitasse a horizontalidade dessa relação (BOURDIEU, 1993; FREIRE, 1986; JODELET, 2003).

Desdeo início recusamos a postura neutra, "d'extractionminière", que implicaria uma distanciação radical e objetivante em relação ao objeto de estudo que se supõe neutro. Antes, nos consciencializamos de que quer o pesquisador, quer os participantes e a comunicação que se estabelece entre eles são partes interessadas ("partie prenant") no processo de construção do conhecimento (JODELET, 2003). Procuramos ter sempre presente a responsabilidade ética que nos assiste, tanto mais que fazem parte da população com que trabalhamos jovens, na maior parte dos casos, menores de idade, pessoas vivas que expuseram a sua voz, as suas histórias de vida e os seus sentimentos (BOGDAN; BIKLEN, 2013).

\section{Codificação e análise dos dados}

No referente à codificação de dados, usamos a codificação temática (FLICK, 2005), uma vez que pretendíamos estabelecer o cruzamento entre os dados recolhidos e a triangulação das fontes (AMADO; FERREIRA, 2013; JODELET, 2003).

Os temas, enquanto características relevantes do conteúdo, foram organizados num sistema de categorias construídas previamente a partir do estudo exploratório e do quadro teórico formulado. Esse quadro de categorias foi sendo submetido a "processos de validação enquanto construção social de conhecimento" em distintos momentos (FLICK, 2005, p. 228), e foi, ainda, ajustado em função de algumas categorias emergentes que foram identificadas.

Os dados foram codificados e sistematizados eletronicamente através do programa informático WebQDA. Este software de suporte à análise de dados qualitativos permite a estrutura básica de análise de conteúdo de Laurence Bardin: i) Organização da Análise, ii) Codificação, iii) Categorização, iv) Inferência (SOUZA, COSTA; MOREIRA, 2011).

De forma a termos acesso não apenas à dimensão cognitiva, mas a outras dimensões dos sujeitos do nosso estudo, como a emocional, procuramos analisar tanto o conteúdo das produções verbais como os próprios discursos, por entendermos que o tratamento do material verbal não se esgota naquela análise (MOSCOVICI, 2006). 
No que concerne ao tratamento dos dados, o nosso propósito não foi analisar a sua organização ou estrutura interna em termos de zona periférica e núcleo central, mas antes fazer emergir os elementos que compõem o conteúdo das representações e que permitem a interpretação do mundo e a orientação das ações e dos comportamentos dos sujeitos. Ou seja, abordamos as representações não em termos de "processo", mas em termos de "produto" (ABRIC, 2001; AMADO, CUSOÉ; VAZ-REBELO, 2013).

\section{RESULTADOS E DISCUSSÃO}

Os resultados que aqui apresentamos, e a sua discussão, referemse às últimas questões do guia da entrevista, cuja análise se inseria na última dimensão da matriz categorial - "Participação dos sujeitos no estudo" - e que não foi exposta na tese de doutoramento que subjaz a este artigo.

Esta dimensão está dividida em duas categorias - "Motivação" e "Comentário Final" -, que foram elaboradas previamente, como já explicitamos atrás. Dessas categorias emergiram, posteriormente, algumas subcategorias, cujos resultados passamos a apresentar nas tabelas que se seguem. Salvaguardamos que o número de respostas não corresponde ao número dos participantes, mas à frequência das suas respostas em cada subcategoria.

Apresentamos alguns excertos, cuja transcrição respeita a fluência do discurso tal como foi proferido na oralidade.

\section{Categoria "Motivação"}

QUADRO 4 - Frequência das causas que motivaram os sujeitos a participar na investigação

\begin{tabular}{|c|c|c|c|c|c|c|c|c|}
\hline \multirow{2}{*}{ Subcategorias } & \multicolumn{2}{|c|}{ A. } & \multicolumn{2}{c|}{ E.E. } & \multicolumn{2}{c|}{ P. } & \multicolumn{2}{c|}{ Total } \\
\cline { 2 - 10 } & $f(n)$ & $\%$ & $f(n)$ & $\%$ & $f(n)$ & $\%$ & $f(n)$ & $\%$ \\
\hline "Interesse sobre o tema" & 14 & 60,9 & 3 & 27,3 & 6 & 60 & 23 & 52,3 \\
\hline "Aspectos formais" & 9 & 39,1 & 2 & 18,2 & 2 & 20 & 13 & 29,5 \\
\hline "Compromisso com a investigação" & & & 6 & 54,5 & 2 & 20 & 8 & 18,2 \\
\hline Total & 23 & 100 & 11 & 100 & 10 & 100 & 44 & 100 \\
\hline
\end{tabular}

Fonte: Dados da pesquisa. 
Analisando a resposta à questão "O que o levou a aceitar o convite para participar nesta pesquisa?", verificamos que as motivações dos participantes para colaborar no estudo empírico foram múltiplas:

A primeira subcategoria, "Interesse sobre o tema", foi aquela que maior número de respostas obteve por parte de todos os grupos participantes do estudo (A., E.E., P.). Por um lado, dada a problemática do estudo, sentem que a sua opinião poderá ser um contributo relevante para a) a compreensão do tema em questão, b) a resolução/melhoria dos problemas que o tema levanta, c) a implementação de boas práticas ao nível escolar. Por outro lado, sentem que ao participarem na pesquisa também se podem enriquecer. Vejamos os excertos que se seguem:

A: Oh... porque eu acho que tenho algum conbecimento dos alunos estrangeiros e o meu convívio com eles acho é... ainda é grande. Por isso acho que o meu contributo dá para a entrevista. (Justino. Portugal)

A: [achei que] talvez fosse interessante falar um bocadinho de mim e da minha cultura $e$ talvez melhorar o comportamento dos estrangeiros futuros que irão estudar aqui em Portugal... (Ling. China)

P: [...] como não tinha formação nenbuma na área, porque não ficar a conbecer mais alguma coisa?... ficar a saber mais (D.T. 5)

P: [...] porque acho que é interessante fazer-se esse tipo de estudo para ver também até que ponto os alunos estão ou não integrados e correspondem ou não a... aos desejos de sucesso e de integração da sociedade portuguesa. (D.T. 3)

As respostas evidenciam que, por um lado, o tema do projeto de investigação e o conteúdo das entrevistas era "significativo" para os entrevistados e suficientemente pertinente para despertar neles a curiosidade e o interesse em participarem; por outro lado, ao fazerem parte de uma escola/turma multicultural, todos tinham, potencialmente, alguma experiência, saber, sentimento a comunicar, o que os fez sentir que poderiam desempenhar eficazmente o seu papel (CANNELL; KAHN, 1992).

A segunda subcategoria, "Aspectos formais", inclui respostas que globalmente fazem sobressair a organização e a implementação do trabalho de campo como determinante no assentimento dos participantes, designadamente o fato de a proposta de participação aos alunos e aos E.E. ser feita, numa fase inicial, através do D.T. - elo de ligação entre a escola e a família; a empatia com a investigadora; a própria ordem e calendarização pela qual as entrevistas foram realizadas, o que fez, particularmente, com que o Diretor da escola fosse o último a ser entrevistado, possibilitando uma opinião mais global do contexto. Ainda referente a esse item, a entrevista ao Diretor coincidiu com as férias escolares, altura em que as orientações do Ministério da Educação para o novo ano escolar estavam a ser 
recebidas pela escola, o que permitiu a tomada de conhecimento das alterações legislativas a serem operacionalizadas já no arranque do ano letivo seguinte. Para além desses aspectos, há ainda algumas respostas que destacam o próprio desenho da investigação, centrada na voz dos alunos - participantes principais do estudo. Os depoimentos que se seguem ilustram a nossa análise:

A: ah... A professora perguntou e... como eu tenho tempo livre... não me fazia diferença a mim, vir... en ofereci-me. (Joaquim. Portugal)

A: [...] porque parecia uma senhora simpática (sorriso)... (Odete. Guiné-Bissau)

D: [...] Por outro lado, o fato desta entrevista ser feita nesta altura, estamos no início de um ano escolar [...] [temos] hoje medidas diferentes do que tínhamos há uns meses atrás [...] posso já adiantar algumas coisas que não foram adiantadas. (Diretor)

P: [...] e achei muito importante, sobretudo, o trabalhar com os miúdos e ouvi-los e trazê-los e tratar esses dados de forma cientifica (D.T.1)

Constatamos assim que, sobretudo quando se trata de uma entrevista qualitativa em que a comunicação se estabelece face a face, a atenção aos aspectos formais deve ser privilegiada, sob pena de a entrevista ser transformada num encontro meramente pontual, arbitrário e ocasional, em vez de um momento propiciador de "uma relação de escuta ativa e metódica” (AMADO; FERREIRA, 2013, p. 212), onde o inter-humano acontece e é passível de se constituir como um caminho de sentido (BOGDAN; BIKLEN, 2013; BOURDIEU, 1993; CANNELL; KAHN, 1992).

A terceira subcategoria, "compromisso com a investigação", refere-se a um "sentimento de dever" em colaborar com a investigação no geral, e não apenas com esta em particular. Esse "compromisso" é justificado de formas diversas: alguns E.E. estrangeiros fundamentam a sua resposta no sentido de darem a conhecer as suas comunidades de pertença; outros E.E. fundamentam que já tiveram de realizar trabalhos acadêmicos de pesquisa, quer enquanto alunos, quer inerentes à sua profissão; por fim, o Diretor justifica que, para além de o estudo dizer respeito à escola, sente o dever de colaborar com a própria Universidade, uma vez que esta também se tem mostrado sempre disponível quando solicitada. Vejamos:

E.E.: [...] Eu digo sempre que nós somos de outro país, há muitos coisas que... se eu não ajudo voce e... isso tudo junto. Nós firemos muitas coisas [...] Participamos sempre... (E.E. Vladislav. Ucrânia)

E.E.: Olhe, eu já fir, durante todo o meu percurso acadêmico, fir trabalbos de campo, fir pesquisas e acho que... é quase um dever moral. Precisei que as pessoas colaborassem comigo e portanto acho que... [...] não posso exigir aos outros nada que não dêprimeiro... (E.E. Assunção. Portugal)

D: Eu acho que primeiro porque é uma obrigação da própria escola participar neste tipo de levantamento e neste tipo de estudo, nestas temáticas e noutras [...] Por outro lado, o bom 
relacionamento e o bom, o bom... sempre bom trabalho que nós tivemos com a Universidade [...] a própria Universidade está sempre atenta quando nós solicitamos [...] E tem-nos ajudado bastante!" (Diretor)

A análise destes resultados leva-nos a concluir que as principais motivações, comuns a todos os grupos participantes do estudo, estão diretamente relacionadas com o mesmo, seja pelo seu conteúdo "interesse sobre o tema" -, seja pelos procedimentos inerentes ao processo - "aspectos formais".

O fato de os participantes terem assinalado o "sentimento de dever" é revelador de um certo grau de compromisso ético, já evidenciado nas motivações expostas, relativamente a) à construção de conhecimento que venha a contribuir para uma melhoria dos contextos escolar e social em que estão inseridos (CASA NOVA, 2011; SANTOS, 2006); b) à própria investigadora, função que já assumiram enquanto estudantes ou profissionais, mostrando neste sentido um certo sentimento de solidariedade; c) à própria Universidade, que tem fornecido respostas às necessidades práticas da escola em que o estudo foi implementado (ALARCÃO, 2001).

\section{Categoria "Comentário Final”}

Quando analisamos os dados referentes aos comentários finais sobre a entrevista e a confirmação ou não das expectativas dos participantes em relação à mesma, emergiram três subcategorias que traduziram esse momento como uma "oportunidade de comunicação", uma "oportunidade de reflexão" e, por fim, uma "oportunidade de potenciar a mudança".

QUADRO 5 - Frequência das respostas sobre 0 comentário final da entrevista

\begin{tabular}{|c|c|c|c|c|c|c|c|c|}
\hline \multirow{2}{*}{ Subcategorias } & \multicolumn{2}{|c|}{ A. } & \multicolumn{2}{c|}{ E.E. } & \multicolumn{2}{c|}{ P. } & \multicolumn{2}{c|}{ Total } \\
\cline { 2 - 11 } & $f(n)$ & $\%$ & $f(n)$ & $\%$ & $f(n)$ & $\%$ & $f(n)$ & $\%$ \\
\hline “Oportunidade de comunicação" & 7 & 31,8 & 7 & 50 & & & 14 & 29,2 \\
\hline "Oportunidade de reflexão" & 8 & 36,4 & 4 & 28,6 & 5 & 41,7 & 17 & 35,4 \\
\hline $\begin{array}{c}\text { "Oportunidade de potenciar a } \\
\text { mudança" }\end{array}$ & 7 & 31,8 & 3 & 21,4 & 7 & 58,3 & 17 & 35,4 \\
\hline Total & 22 & 100 & 14 & 100 & 12 & 100 & 48 & 100 \\
\hline
\end{tabular}

Fonte: Dados da pesquisa. 
A primeira subcategoria, "oportunidade de comunicação", acolheu parte das respostas dos alunos e dos Encarregados de Educação e traduz um momento em que estes sentem que se podem expressar, podem fazer ouvir a sua vOz e partilhar as suas experiências de vida e emoções, como podemos verificar pelos excertos que se seguem:

A: $[\ldots]$ poder partilhar as minhas experiências quando vim pra cá para poder ajudar ah... no fundo, a este trabalho. (Kirill. Ucrânia)

A: [...] talvez como se fosse um resumo de tudo o que eu passei... na escola portuguesa durante os últimos anos... e fosse um desabafo pra... com a professora... [...] e consegui. Consegui expressar-me. (Ling. China)

E.E.: Foi muito agradável, quase que não foi responder a questões, foi uma conversa... (E.E. Assunção. Portugal)

Nessa partilha, os E.E. sublinharam o seu agrado por as vozes dos seus filhos terem sido escutadas e as experiências dos mesmos terem sido valorizadas. Alguns afirmam que a entrevista foi um incentivo para os próprios educandos:

E.E.: Olha, primeiro fiquei satisfeita porque é uma coisa que ajudou, en acho que ajudou ele. Antes ele estava um pouco mais desinteressado. Agora está mais interessado e ajudou bastante (E.E. Júlio. Brasil)

E.E.: [...] Gostei que você 'tá interessada em saber do ... do meu filho... (E.E. Vladislav. Ucrânia)

Embora a entrevista de investigação científica se distinga das entrevistas terapêuticas - particularmente nos objetivos a que se propõe e nos procedimentos usados (KVALE, 1996) -, apuramos que o momento da entrevista representou uma oportunidade de comunicação que se traduziu num momento de "libertação", como uma "terapia" em relação a experiências dolorosas que alguns alunos e E.E. tinham vivenciado e cuja partilha os fez "sentir melhor". Subjazem a estas opiniões vivências escolares que traduzem episódios de discriminação racial, cultural ou linguística, entre outras:

A: «como foi a entrevista?» (repete a questão) Foi... foi difícil lembrar essas coisas, essa parte menos boa da minha vida... [...] foi bom, até foi libertador (Lucas. Venezuela)

A: [...] e acho que esta pesquisa para mim serviu de terapia, é mais para isso [...] é como se fosse preciso desabafar aquilo tudo e depois «ai agora jáposso seguirpara a frente!...» (Eugénia. Angola)

A: [...] acho que ajuda um bocadinho a desabafar com alguém [...] tinha medo de dizer como é que tratavam as pessoas na escola, porque... não sei... acho que não tinha confiança com as pessoas mais velhas para contar isso... [...] foi positivo, só ouvindo, ajuda um bocadinho... já é uma ajuda! (Olena. Ucrânia)

E.E.: [...] pronto, fez-me sentir melhor... (E.E. Ramiro. Portugal)

Assim, o momento da entrevista enquanto oportunidade de comunicação para estes dois grupos (A. e E.E.) lembra-nos o 
quão importante deve ser a valorização dos saberes de origem e as experiências dos alunos e das suas famílias, de forma a considerá-los “escolarmente rentáveis" (CANDAU, 2012), contra o desperdício da experiência social (SANTOS, 2006). Sublinhamos, ainda, que esta oportunidade de comunicação é tanto mais importante quanto verificamos que, no nosso estudo, alguns dos alunos que sentem que foram sujeitos a experiências de preconceito ou discriminação raramente partilham essas experiências - quer em casa, quer na escola -, ou porque passaram a considerar essas situações "normais", ou porque não creem que os seus professores ou D.T. possam resolvê-las.

Uma segunda subcategoriarefere-seà entrevista comouma "oportunidade de reflexão", reflexão sobre um tema que lhes interessa, mas sobre o qual "não costumam pensar"; reflexão sobre a importância da autenticidade das suas respostas e dos seus sentimentos; reflexão que permite, acima de tudo, a consciencialização de preconceitos e estereótipos, de múltiplas contradições e da falta de fundamentação em algumas das suas opiniões. Vejamos alguns excertos ilustrativos desta análise:

A: [...] Algumas questões não foram fáceis porque nunca tinha pensado nelas, mas outras, outras foram... foram boas e até a darmos a nossa maneira, de explicarmos a nossa maneira de pensar e... não temos de fazer parecer que as coisas são sempre bem, quando elas não são. (Carolina. Portugal)

A: Howve algumas coisas um bocado complicadas porque... porque tinha aquela ideia formada, mas que depois para estar a desenvolver aquilo épreciso pensar um bocado e... às vezes começava-me a faltar um bocado de razão, entre aspas, on de razões naquilo que estava a dižer. (Ronaldo. Portugal)

A: Às vezes foi difícil (sorriso)... às vezes não sabia justificar as minhas escolbas... dar exemplos... (Kirill. Ucrânia)

P: Foi agradável... [...] Às vez̨es, a pessoa entra em contradição. (D.T. 4)

Essa entrevista ainda possibilitou, por parte de alguns E.E., a reflexão sobre a evolução da escola portuguesa ao longo dos últimos anos e a sua progressiva afirmação enquanto escola intercultural e interlinguística, bem como a comparação com as escolas dos países de origem de alguns E.E. estrangeiros. Usam essa comparação para sublinhar as boas práticas que entendem que a escola portuguesa tem vindo a promover:

[A propósito dos problemas que teve com a professora primária que responsabilizava esta E.E. pelo atraso na aprendizagem da leitura do seu educando, dado falar em Francês no espaço doméstico]:

E.E.: acho que me ficou uma dor muito grande daquele primeiro ano do meu filho $[. .$.$] até fico$ mais aliviada porque, 12 anos mais tarde, as pessoas concordam comigo que aquilo não fazia sentido [...] Cá em Portugal tem evoluído muito, muito... (E.E. Ramiro. Portugal)

E.E.: [...] ... en na escola apanhei... apanhei sempre o trabalho excelente com o meu filho. Ele nunca ficou... nunca ficou [de] lado, não! Tava sempre bem tratado, eu digo e... digo a 
toda a gente: lá na Ucrânia não tenho certeza se alguém de... dos portugueses, se queria viver na Ucrânia e leva o seu filho, [não sei se] apanha apoio como apanhou o meu filho [...] Tenho certęa que não! Tenho certęa que não!... (E.E. Vladislav. Ucrânia)

E.E: Não quero que as escolas daqui cheguem àquele ponto, àquela tristeza que é o Brasil. $[$...] ... muita criança inocente não tem a paž e tranquilidade que bá aqui. [...] No seu princípio, logo que ele chegou, e não tinha conbecimento com ninguém, ele teve um grande apoio. Ganhou os livros todos de um colega lá que mandou pra escola e eles doaram para ele. (E.E. Júlio. Brasil)

Essa "oportunidade de reflexão" que os participantes dizem sentir confirma como a pesquisa pode encetar nos mesmos um processo de "conscientização" dos seus contextos de vida (FREIRE, 1986, 1994), tanto numa perspectiva diacrônica, em que estabelecem um paralelo entre o passado e o presente da escola portuguesa, como numa perspectiva sincrônica, em que traçam um paralelo entre as escolas dos seus países de origem e a escola do país de acolhimento.

O grupo dos professores, por sua vez, encara esta entrevista como uma oportunidade para refletirem sobre a presença dos alunos estrangeiros na escola - presença essa considerada positiva - e aquilo que falta fazer ou pode vir a ser melhorado, quer relativamente às suas práticas em sala de aula, quer ao nível da escola em geral, a favor dos alunos e dos seus projetos futuros:

P: [...] Esperava poder também refletir, ao mesmo tempo, não é? Fazer uma entrevista é também uma oportunidade para eu refletir sobre as minhas práticas e as estratégias que tenho adotado e também um pouco o que é que se passa na escola e descobrir que falta saber algumas coisas na escola. (D.T. 3)

D: [...] neste caso eu, como Diretor, e os outros elementos que foram entrevistados também serem questionados sobre algumas coisas que, se calhar, nós não nos apercebemos que elas poderão ser questionadas, não é? O levantar questões, o vir elementos... um elemento de fora levantar questões dentro de um organismo, neste caso a escola, é muito positivo porque pode trazer questões que nós não colocamos. (Diretor)

Esse momento como "oportunidade de reflexão" para os professores é tanto mais importante quanto se verifica a denúncia por parte desses profissionais de várias dificuldades que consideram constranger a sua atividade docente, como a exigência da "transmissão de conhecimentos", o cumprimento dos Programas por parte do Ministério da Educação, a extensão dos mesmos, o tempo que consideram "pouco" para o seu cumprimento, a pressão dos Exames Nacionais e dos "rankings" das escolas, o excessivo número de alunos por turma e a heterogeneidade das mesmas, a excessiva burocratização do seu trabalho e da avaliação a que estão sujeitos:

P: [...] portanto ... acho que estamos... é o problema da transmissão de conbecimentos, quer dižer, o cumprimento de programas, a questão de exames depois no fim nalgumas disciplinas acaba por nos pôr umas palas que parece que só vemos a... a questão das disciplinas e pouco mais... (D.T.4) 
P: [...] Como é que eles... querem que nos tornemos melhores professores se não nos deixam fazer o nosso trabalho porque nos ocupam o tempo com outras coisas? (D.T.5)

Lembramos que essas dificuldades são comuns a muitos docentes que, para além dos fatores apontados, têm vindo a travar a nível nacional uma luta contra algumas medidas do Ministério da Educação que sentem afetar os seus interesses corporativos, o que alerta também para a absoluta necessidade de condições contextuais que não desviem, mas antes favoreçam, as capacidades de reflexão crítica e a "disponibilidade emocional" dos professores. Neste contexto, sentimos, ainda, que a participação dos Professores na investigação não deixa de ser um ato de "generosidade" (CORTESÃO, 2012).

A terceira subcategoria diz respeitoà entrevista como oportunidade de "potenciar a mudança" a um nível social e institucional, dentro e fora da sala de aula. Assim, os grupos dos alunos e dos E.E. acreditam que os seus depoimentos podem ajudar a aumentar o conhecimento sobre os alunos estrangeiros na escola, as suas comunidades, as suas culturas e línguas; superar os problemas de integração aos quais alguns deles estiveram sujeitos; combater os preconceitos contra as "pessoas diferentes" e os estereótipos sobre determinadas comunidades; contribuir para uma maior abertura e uma convivência de maior qualidade entre alunos autóctones e estrangeiros; incentivar a aprendizagem de outra(s) língua(s) para além das europeias:

\footnotetext{
A: $[\ldots]$ pronto, foi... foi bom ... foi bom porque... para... pronto, para alguém saber qualquer coisa sobre os ucranianos (Vladislav. Ucrânia)
}

A: Porque... porque eu acho que ainda há muito preconceito acerca de pessoas diferentes e acho que se pudermos fazer qualquer coisa on ajudar no projeto on ajudar a que seja realizada alguma coisa para isso mudar, acho que devemos! É mais ou menos como dar sangue! (Assunção. Portugal)

E.E.: [...] Porque muitas vezes as pessoas podem achar «ah, está por aqui para encostar ou por dinheiro». Não é! Não é! ${ }^{9}$ [...] E não tenho medo, não tenho medo por estar aqui em Portugal. Tinha medo se estivesse a fazer alguma coisa de errado... (E.E. Júlio. Brasil)

E.E.: [...] Os hábitos dos alunos chineses eu gostava que eles... eles conbecessem melhor. [...] incentivava mais a aprender a lingua, acho eu. Claro que aprender uma lingua que nunca fala é um bocado difícil mas seria interessante, interessante para eles aprenderem as diferenças [...] seria ótimo... por exemplo, para abrir mais as mentes (E.E. Paul. França)

O grupo dos professores, por sua vez, propõe um ajuste entre os currículos de algumas disciplinas e as realidades dos alunos que estão na turma e alerta para a necessidade de iniciativas concretas que estimulem a própria subjetividade dos diversos agentes educativos, nas suas múltiplas diversidades, em contexto escolar. Repare-se como a última frase do segundo excerto constata a importância do "ambiente ecológico" tal como o mesmo é percebido e não como existência 
objetiva, para o qual Bronfenbrenner (2002) chama a atenção das pesquisas contemporâneas:

P: [...] se eu continuar a ser D.T. e se tiver alunos estrangeiros, podemos realmente ter uma unidade a tratar das várias culturas dos alunos da turma, dessas nacionalidades. É capaz de ser um bom tema porque nós na Formação Cívica andamos sempre à procura de temas [sorriso] que tenham a ver com a turma [...] realmente esse é um tema que dá perfeitamente para tratar e fazer um trabalho giro sobre isso... (D.T.2)

P: [...] isso até me fazpensar agora, mas também só estou a pensar agora por causa de estar a ter esta entrevista, faz-me pensar que às tantas há necessidade também de criar algumas, até se pode propor isso à Direção, criar algumas iniciativas a nivel de escola [...] A necessidade que eu acho que há de conhecermos a nossa realidade, não necessariamente como ela é, mas como as pessoas se sentem e se veem nela... (D.T.1)

A reflexão ao nível institucional estende-se à própria Universidade e à proposta de introdução de Unidades Curriculares mais consentâneas com as realidades que os alunos, futuros professores, encontrarão nas escolas, designadamente a introdução de uma Unidade Curricular que os prepare para a realidade das escolas multiculturais. Pelo testemunho que se segue, a professora, apesar de ser a mais jovem deste grupo e tendo frequentado há poucos anos um curso de Licenciatura via Ensino, denuncia não ter tido qualquer formação na área da interculturalidade. Pese embora, enquanto docente, essa necessidade de formação acadêmica, a condição pessoal também não foi esquecida:

P: $[. .$.$] porque não numa das cadeiras de uma licenciatura de ensino integrar uma cadeira deste$ género de educação intercultural?! [...] Cada vez mais temos alunos com etnias diferentes e com proveniências diferentes, porque não integrar uma disciplina?! [...] Estas perguntas fazem-nos pensar em muitas coisas que se calbar não pensamos na nossa vida normal e se calhar alertar-me para algumas situações... [...] Eu não estava a falar só de conhecimento acadêmico, mas en própria como pessoa, tentar adquirir... uma outra postura, se calbar... (D.T.5)

Para aqueles professores que fizeram formação nessa área, a entrevista levou-os à necessidade de reavivarem esses conhecimentos, reatando contacto também consigo próprios:

P: [...] Olhe, en vou dizer uma coisa e isso en senti! e senti sobretudo na primeira parte da entrevista!... Eu andava como que adormecida, como é que eu hei-de dizer?, acho que pra mim foi muito bom porque me forçou a reencontrar-me comigo própria [...] o que é fato é que me fui afastando, estou com os miúdos e eu até tenho esta coisa de... de ensinar muito a perspetiva e a relatividade, mas... acho que tinha perdido o contacto com o fundo, e esta entrevista permitiu-me reatar contactos comigo própria, mesmo!... (D.T.1)

Verificamos após esta análise de resultados que as subcategorias que colhem mais assentimento por parte de todos os grupos entrevistados são a "oportunidade de reflexão" e a "oportunidade de 
potenciação da mudança". Essa constatação remete-nos para o fato de que, apesar de o nosso estudo não ser uma investigação-ação, e o nosso instrumento principal de recolha de dados não ser uma entrevista de cariz interventivo (Okolie, 2008), as respostas que validaram esta técnica de recolha de dados sublinham como a própria experiência de participação dos sujeitos na investigação e a sua consequente reflexão sobre essa participação podem também criar condições para a construção de uma epistemologia emancipatória. Particularmente para os professores, algumas respostas vão no sentido da necessidade de se assumirem como educadores progressistas que promovam a responsabilidade ética e social do que ensinam e como o ensinam (APPLE, 1999; FREIRE, 1994, 2001; MCLAREN; GUTIERREZ, 2000).

Se educar é formar o indivíduo para a criatividade, não por causa do conteúdo do conhecimento transferido, mas para que o próprio processo de aprender espicace a "capacidade de arriscar-se, de aventurar-se", o que "de certa forma o imuniza contra o poder apassivador do bancarismo" (FREIRE, 2001, p. 28), então a formação de futuros professores e a formação contínua daqueles docentes que já estão em exercício deve fazê-los investigadores de outras temáticas educativas para além das específicas e investigadores, também, dos seus futuros/atuais alunos, através de métodos dialogantes e participativos passíveis da reconstrução do mundo (FREIRE, 1994).

\section{CONSIDERAÇÕES FINAIS}

Promover a pesquisa e a reflexão sobre o mero processo de questionar/investigar na escola, com e sobre os alunos e as suas representações, pode por si só potenciar a intervenção no campo educativo e a missão social de viver, conviver e intervir em interação com os outros cidadãos (ALARCÃO, 2007; LINCOLN; GUBA, 2006).

Relativamente às representações da escola e às funções da mesma face à sociedade culturalmente diversa e em mudança, constatamos como a entrevista - que neste caso privilegiou questões abertas - permitiu que os participantes revelassem algumas representações positivas da escola portuguesa e da sua evolução face ao contexto social e histórico marcado pelos fenômenos migratórios. Ao mesmo tempo, também permitiu o questionamento do sistema de funcionamento da escola e a análise de aspectos que devem ser implementados ou melhorados com vista a uma escola e a uma educação não apenas multicultural, mas, sobretudo, intercultural (ABRIC, 2000; GILLY, 1989; JODELET, 2003). 
Constatamos ainda, pela análise e discussão dos resultados relativos às questões que validaram a entrevista, que essas questões permitiram aos participantes uma metarreflexão que impossibilitou que se instalassem na leitura que faziam da escola. Nessa conformidade, sublinhamos que pesquisar com os alunos e os demais agentes educativos, e não apenas sobre eles, é também estimular, por um lado, uma "transição epistemológica" de uma maneira mais ingênua de pensar para outra mais crítica de compreender a escola e a sociedade e, por outro lado, uma "transição ecológica" que lhes permite superar a mera constatação, refletir e projetar mudanças, não apenas relativas aos ambientes imediatos em que se inserem, como a sala de aula e a escola, mas também relativamente às influências de contextos mais amplos em que estes ambientes estão incluídos e com os quais estabelecem interconexões, particularmente, no caso do nosso estudo, a necessidade de formação de futuros professores em educação intercultural ou o combate social contra os estereótipos sobre algumas comunidades de imigrantes.

Na nossa opinião, a entrevista pode ser entendida como um instrumento crítico de análise do contexto educativo e das práticas que nele ocorrem, dentro e fora da sala de aula, capaz de fomentar a autonomia dos sujeitos e a sua racionalidade crítica, encorajando a passagem de receptor de um sentido cultural, socialmente construído, para agente da sua própria prática cognitiva e ecológica no mundo.

São necessárias atividades que questionem a escola, o seu funcionamento, a sua estrutura, para ajudar a inverter a tendência de remeter para fora da escola a explicação das desigualdades que se verificam dentro dela. São necessárias ações que levem os agentes educativos a assumir outros papéis, a desempenhar novas atividades e a interagir com novas pessoas, de forma a potenciar - dentro de um clima escolar de disponibilidade emocional e reflexão crítica - uma maior capacidade de compreensão e a consequente intervenção.

Por fim, cumpre-nos reconhecer a importância do Estudo Exploratório que precedeu o estudo principal que subjaz a este artigo, a) pelos ajustes que nos permitiu fazer ao guia da entrevista, b) pela riqueza de dados que exigiu o aprofundamento do enquadramento teórico, c) pela experiência que nos proporcionou, enquanto entrevistadores, para encetar conscientemente esta relação com os sujeitos participantes, estabelecendo as "regras do jogo", os objetivos e as práticas negociadas de um processo que pretendíamos bem determinado, de modo a minimizar o "viés das coisas" (Bourdieu, 1993; Stake 2007). 
Consideramos imprescindível a realização dessa etapa do processo investigativo, não devendo a mesma ser inviabilizada pelo cumprimento dos prazos de duração dos programas de doutoramento e investigação.

\section{REFERÊNCIAS}

ABRIC, Jean-Claude. A Abordagem Estrutural das Representações Sociais. In: MOREIRA, António Silva; OLIVEIRA, Denize Cristina de (Orgs.). Estudos Interdisciplinares de Representacõoes Sociais. Goiânia: AB Editora, 2000. p. 27-38.

ABRIC, Jean-Claude. (Dir.). Pratiques sociales et représentations. 3. ed. Paris: PUF, 2001.

ALARCÃO, Isabel. Escola Reflexiva. In: ALARCÃO, Isabel. (Org.). Escola Reflexiva e Nova Racionalidade. Porto Alegre: Artmed Editora, 2007. p. 15-30.

ALARCÃO, Isabel. Professor-investigador: Que sentido? Que formação? Cadernos de formação de professores, Aveiro, n. 1, p. 21-30, 2001.

AMADO, João; FERREIRA, Sónia. A entrevista na investigação educacional. In: AMADO, João (Coord.). Manual de Investigação Qualitativa em Educação. Coimbra: Imprensa da Universidade de Coimbra, 2013. p. 207-232.

AMADO, João. A investigação em educação e seus paradigmas. In: AMADO, João (Coord.). Manual de Investigação Qualitativa em Educação. Coimbra: Imprensa da Universidade de Coimbra, 2013. p. 19-71.

AMADO, João; CUSOÉ, Nilma; VAZ-REBELO, Piedade. Quadros Analíticos da Investigação Qualitativa em Educação. In: AMADO, João (Coord.). Manual de Investigação Qualitativa em Educação. Coimbra: Imprensa da Universidade de Coimbra, 2013. p. 73-115.

APPLE, Michael. Políticas Culturais e Educação. Porto: Porto Editora, 1999.

BOGDAN, Robert; BIKLEN, Sari. Investigação qualitativa em educação: uma introdução à teoria e aos métodos. Porto: Porto Editora, 2013.

BOGDAN, Robert; TAYLOR, Steven. Introduction to qualitative research methods: a phenomenological approach to the social sciences. New York: John Wiley \& Sons, 1975.

BOURDIEU, Pierre. (Dir.). La misère du monde. Paris: Seuil/ Collection Points, 1993.

BRONFENBRENNER, Urie. A ecologia do desenvolvimento bumano: experimentos naturais e planejados. Porto Alegre: Artmed, 2002.

CANDAU, Vera. Didática: Entre Saberes, Sujeitos e Práticas. In: ENDIPE - ENCONTRO NACIONAL DE DIDÁTICA E PRÁTICAS DE ENSINO - UNICAMP, 16., 2012, Campinas. Campinas: Junqueira \& Marin Editores, 2012. p. 1-13.

CANNELL, Charles; KAHN, Robert. La reunion de datos mediante entrevistas. In: FESTINGER, Leon; KATZ, Daniel (Org.). Los métodos de investigación en las ciências sociales. Barcelona: Editorial Paidós, 1992. p. 310-352.

CARTWRIGHT, Dorwin. Analisis del material qualitativo. In: FESTINGER, Leon; KATZ, Daniel (Orgs.). Los Métodos de Investigación en las Ciencias Sociales. Barcelona: Editorial Paidós, 1992. p. 389-432.

CASA NOVA, Maria José. A investigacão comprometida: métodos e subjetividades. Comunicação apresentada no Curso de Formação Experiências de Investigação: Metodologias e Desassossegos (16 de fevereiro). Centro de Estudos Sociais da Universidade de Coimbra, 2011. CORTESÃO, Luiza. Discutindo autonomia relativa com professores: A indisciplina como (contra) argumento. Porto: Livpsic, 2012. 
CORTESÃO, Luiza; STOER, Stephen. Projectos, Percursos, Sinergias no Campo da Educação Intercultural: Relatório Final. Porto: FPCEUP/ Edições Afrontamento, 1995.

DENZIN, Norman; LINCOLN, Yvonna. Introdução: a disciplina e a prática da pesquisa qualitativa. In: DENZIN, Norman; LINCOLN, Yvonna (Orgs.). O planejamento da pesquisa qualitativa: Teorias e Abordagens. Porto Alegre: Artmed Editora, 2006. p. 15-41.

FIORI, Ernani. Aprender a dizer a sua palavra. Prefácio. In: FREIRE, Paulo. Pedagogia do Oprimido. São Paulo: Paz e Terra S/A, 1994. p. 5-11.

FLICK, Uwe. Métodos qualitativos na investigação científica. Lisboa: Monitor, 2005.

FODDY, William. Como perguntar: teoria e prática da construção de perguntas em entrevistas e questionários. Oeiras: Celta, 1996.

FREIRE, Paulo. Criando métodos de pesquisa alternativa: aprendendo a fazê-la melhor através da ação. In: BRANDÃO, Carlos Rodrigues. Pesquisa Participante. São Paulo: Brasileirense, 1986, p. 34-41.

FREIRE, Paulo. Pedagogia do oprimido. São Paulo: Paz e Terra S/A, 1994.

FREIRE, Paulo. Pedagogia da autonomia: saberes necessários à prática educativa. São Paulo: Paz e Terra S/A, 2001.

GILLY, Michel. Les représentations sociales dans le champs éducatif. In: JODELET, Denise (Dir.). Les Représentations Sociales. Paris: PUF, 1989. p. 363-386.

JODELET, Denise. Aperçus sur les méthodologies qualitatives. In: MOSCOVICI, Serge; BUSCHINI, Fabrice (Dirs.). Les Méthodes des Sciences Humaines. Paris: PUF, 2003, p. 139-162.

KVALE, Steinar. InterViews: an introduction to qualitative research interviewing. London: SAGE Publications, 1996.

LINCOLN, Yvonna; GUBA, Egon. Controvérsias paradigmáticas, contradições e confluências emergentes. In: DENZIN, Norma; LINCOLN, Yvonna (Orgs.). O Planejamento da Pesquisa Qualitativa: teorias e abordagens. Porto Alegre: Artmed, 2006, p. 169-192.

MCLAREN, Peter; GUTIERREZ, Kris. Política global e antagonismos locais: pesquisa e prática como dissenso e possibilidade. In: MCCLAREN, Peter (Org.). Multiculturalismo revolucionário: pedagogia do dissenso para o novo milénio. Porto Alegre: Artmed Editora, 2000, p. 195-222.

MORIN, Edgar. As grandes questões do nosso tempo. Lisboa: Editorial Notícias, 1994.

MOSCOVICI, Serge. The phenomenon of social representations. In Robert Farr; Serge Moscovici (Eds.). Social Representations. Cambridge: Cambridge University Press, 1984. p. 3-69

MOSCOVICI, Serge. Notes towards a description of Social Representations. European Journal of Social Psychology, 18(3), p. 211-250, 2006. Disponível em: < http://onlinelibrary. wiley.com/doi/10.1002/ejsp.2420180303/pdf>. Acesso em janeiro de 2014.

OKOLIE, Andrew. Para um enquadramento anti-racista da investigação. O caso para entrevistas aprofundadas de cariz interventivo. In: DEI, George Sefa; Johal, Gurpreet (Org.). Metodologias de investigação antirracistas: Questões Críticas. Mangualde: Edições Pedago, 2008, p. 175-214.

PARDAL, Luís; CORREIA, Eugénia. Métodos e técnicas de investigação social. Porto: Areal Editores, 2011.

RUQUOY, Danielle. Situação de entrevista e estratégia do entrevistador. In: ALBARELLO, Luc et al. Práticas e métodos de investigação em ciências sociais. Lisboa: Gradiva, 2005. p. 84-116.

SANTOS, Boaventura de Sousa. A Gramática do Tempo: para uma nova cultura política. Porto: Edições Afrontamento, 2006.

SOUZA, Francislê Neri; COSTA, António Pedro; MOREIRA, António. Análise de Dados Qualitativos Suportada pelo Software WebQDA. In: CONFERÊNCIA INTERNACIONAL 
DE TIC NA EDUCAÇÃO: PERSPETIVAS DE INOVAÇÃO, 7., 2011, Braga. Actas... Braga, 2011, p. 49-56.

STAKE, Robert. $A$ arte da investigação com estudos de caso. Lisboa: Fundação Calouste Gulbenkian, 2007.

TAVARES, José; ALARCÃO, Isabel. Paradigmas de Formação e Investigação no Ensino Superior para o Terceiro Milênio. In: ALARCÃO, Isabel (Org.). Escola Reflexiva e Nova Racionalidade. Porto Alegre: Artmed Editora, 2001, p. 97-114.

\section{NOTAS}

1 "Das Representações Sociais à Educação Intercultural - Identidade/ Alteridade de Alunos Autóctones e Estrangeiros numa Escola Multicultural" - tese de doutoramento em Didática e Formação, Ramo de Desenvolvimento Curricular, concluída em janeiro de 2014 na Universidade de Aveiro, Departamento de Educação, com o apoio financeiro da DGAE - Ministério da Educação. ${ }^{2}$ Os sítios da Internet referidos ao longo deste artigo encontravam-se ativos em novembro de 2015. ${ }^{3} \mathrm{O}$ " $3^{\circ}$ Ciclo" do sistema educativo português inclui os $7^{\circ}, 8^{\circ}$ e $9^{\circ}$ anos, que correspondem aos três últimos anos do "Ensino Fundamental" no sistema de educação brasileiro. O "Ensino Secundário", por sua vez, corresponde no Brasil ao "Ensino Médio".

${ }^{4}$ Ver também: ALARCÃO, 2007.

${ }^{5}$ PALOP - Países Africanos de Língua Oficial Portuguesa.

${ }^{6}$ O Encarregado de Educação, segundo o Despacho n. ${ }^{\circ} 14$ 026/2007, de 3 de julho, do Ministério da Educação, é o sujeito que tiver menores à sua guarda nas seguintes condições: pelo exercício do poder paternal; por decisão judicial ou pelo exercício de funções executivas na direção de instituições que tenham menores à sua responsabilidade. Disponível em: $<$ http://legislacao.min-edu.pt/>. Acesso em janeiro de 2014.

${ }^{7}$ Seguimos a seguinte escala: 28-34 anos; 39-44 anos; 45-51 anos.

${ }^{8}$ Veja-se o artigo $7 .^{\circ}$ do Decreto Regulamentar n. ${ }^{\circ}$ 10/99, de 21 de julho, relativo às competências do Diretor de Turma. Disponível em: < http://legislacao.min-edu.pt/>. Acesso em janeiro de 2014.

${ }^{9}$ Seguimos a seguinte escala: 5-10 anos; 22-24 anos; 27-30 anos.

${ }^{10}$ Esta E.E. refere-se aos estereótipos na sociedade portuguesa sobre os brasileiros. Nas suas palavras: "ouvi também é que as mulheres e os homens durante o dia dormem, e durante a noite vão para a malandrice, os brasileiros, não é? (...) «os brasileiros estão aí mas é assim, dormem o dia e à noite saem para roubar e se prostituir!»".

Recebido: 08/08/2014

Aprovado: 08/07/2015

Contato:

Universidade de Aveiro LEIP. Laboratório de Investigação em Educação em Português Departamento de Educação Campus Universitário de Santiago. Aveiro. Portugal 